\title{
Experimental and Molecular Level Analysis of the Tribological and Oxidative Properties of Chaulmoogra Oil
}

\author{
S. Salaji (i) and N. H. Jayadas $(\mathbb{D}$ \\ School of Engineering, Cochin University of Science and Technology, Cochin, Kerala 682022, India \\ Correspondence should be addressed to S.Salaji; salajis@cusat.ac.in
}

Received 4 May 2020; Revised 18 September 2020; Accepted 25 September 2020; Published 17 October 2020

Academic Editor: Dae-Eun Kim

Copyright (๑) 2020 S. Salaji and N. H. Jayadas. This is an open access article distributed under the Creative Commons Attribution License, which permits unrestricted use, distribution, and reproduction in any medium, provided the original work is properly cited.

\begin{abstract}
This study introduces chaulmoogra oil as a base stock for lubricant formulation. The tribological properties of chaulmoogra oil are evaluated by quantitative structure-property relation (QSPR) technique using the molecular modelling package Spartan 18. The quantum chemical calculations were performed on a typical molecule of chaulmoogra oil and its constituent fatty acids. The orbital energy gap of the constituent fatty acids in chaulmoogra oil is $7.37 \mathrm{eV}$ and that of chaulmoogra oil molecule is $6.8 \mathrm{eV}$, which is less than that of the lauric acid, the main constituent of coconut oil $(7.78 \mathrm{eV})$. Orbital energy gap predicts a better tribological performance for chaulmoogra oil, and the four ball test result is in agreement with this prediction. Oxidative property of chaulmoogra oil is tested by isothermal thermogravimetric/differential thermal analysis (TGA/DTA) and compared with different oils. Weight gain in oxygen is only $0.02 \%$ for chaulmoogra oil and showed better oxidative stability among all other tested oils.
\end{abstract}

\section{Introduction}

There is a surge of identifying new materials for developing lubricant base stock. As a natural material, vegetable oils are getting attraction and are proved to be the best biodegradable and renewable substitute for mineral oil in lubricant formulation. Vegetable oils have some excellent properties such as high lubricity, high viscosity index, high flash point, and low evaporative loss [1-4], but the cold flow properties, oxidation stability, and hydrolytic stability are poor $[5,6]$. A number of edible oils are used as lubricant base stock. However, the use of edible oil in industrial application causes price escalation and scarcity of these oils for food purpose [7]. Now it became a necessity to identify materials that cause less harm to nature and does not create a negative impact on human consumption. India is blessed with rich biodiversity consisting of unique plants, and many nonedible oils can be identified as a substitute material for mineral oil. This paper introduces chaulmoogra oil (Hydnocarpus wightianus) as a new biodegradable and nonedible lubricant base stock, and its antiwear property and oxidative stability are evaluated by fast test methods and compared with other saturated and unsaturated oils. The novelty in this study is the prediction of the antiwear property of chaulmoogra oil by QSPR technique and comparison of oxidation stability of chaulmoogra oil with saturated and unsaturated oil using isothermal TGA/DTA. Also, chaulmoogra oil is a unique nonedible oil due to the presence of long-chain cyclic fatty acids such as hydnocarpic acid, chaulmoogric acid, and gorlic acid. Chaulmoogra tree grows in wild forests of India and other countries. This tree is abundant in the villages of Kerala. Chaulmoogra oil is useful for the treatment of skin disorders and leprosy. A few years back, the folks of Kerala used this oil for lighting lamp. Now a significant portion of the seed is wasted as its benefits and market are not well established.

Vegetable oils are triacylglycerides (TAGs), and the general structure is shown in Figure 1 [8], where $R_{1}, R_{2}$, and $\mathrm{R}_{3}$ represent the hydrocarbon chain of different fatty acids. Some exceptions are present like jojoba oil which is liquid wax [9]. Typical vegetable oils contain a combination of saturated and unsaturated fatty acids, with the double bond in the cis-configuration. Some vegetable oils contain fatty acids with chemical functionality [10]. Fatty acids present in 


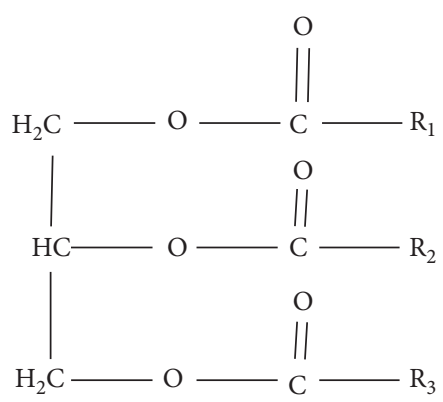

Figure 1: Structure of TAG [8].

the oil determine the bulk properties of the oil. Evaluation of vegetable oils for industrial use requires many time-consuming and expensive tests. Many standard test methods are available to evaluate the antiwear characteristics of vegetable oil. Pin on disc (ASTM G99, DIN 50324) and four ball tests (ASTM 4172) are generally used for evaluating antiwear properties, but these test methods are costly and require mechanical hardware. Quantitative structure-property relation (QSPR) is an inexpensive and fast technique to screen and evaluate triacylglycerides for industrial application $[11,12]$. The antiwear characteristics of fatty acids and triacylglycerides hinge on the three phenomena: physical adsorption, chemical adsorption, and surface chemical reaction [13]. These phenomena occur due to the interaction of the polar group in the fatty acids with the metallic surface. In boundary lubrication, polar heads of fatty acids adhere to the metal surface and form a monolayer [14]. This monolayer reduces friction between surfaces. This can be well explained with QSPR techniques. It is assumed that the electronic structure of the polar group is not affected by the ester linkage [11]. Hence, instead of analyzing the complex molecule of triglycerides, the properties that depend on the electronic structure of the polar group can be assessed by the fatty acid constituents. For a preliminary screening of new vegetable oil, the QSPR technique is effective and enables a fast comparison of its antiwear characteristics with some well-known oils in use.

Another disadvantage of vegetable oil is its poor oxidation stability. Oxidative property can predict long-term stability of oils in industrial application, especially as a lubricant. The formation of undesirable deposits, sludge, and corrosive by-products can be suppressed if the lubricant is resistant to oxidation. Oxidation rate increases with the degree of unsaturation.

Oxidation reaction starts with the formation of hydroperoxides through free radical mechanism. Allyl proton in unsaturated fatty acid is associated with less bond energy. This proton gets detached from the hydrocarbon chain and produces a free radical. The free radical then reacts with oxygen to produce highly reactive peroxy radicals. Another free radical is produced when the reactive peroxy radicals take protons from other fatty acid molecules and form hydroperoxide. Hydroperoxides then degrade to secondary oxidation products such as alcohols, aldehydes, ketones, epoxides, dimers, and polymers [15]. This leads to the rancidity of oil. The presence of various protons (olefinic, allylic, and bis-allylic protons) and cyclic fatty acids are confirmed using Fourier-transform infrared spectroscopy (FTIR) and nuclear magnetic resonance (NMR) spectroscopy. If the contact surface is water free, metals in the presence of air may react with different components in the oil or with the dissolved oxygen and get corroded [16]. In the presence of water, these reactions become more complicated [17]. Even without oxygen, air, or water, thermal degradation due to the pyrolytic reaction may occur at high temperature. The degradation of cyclic fatty acid produces many low-molecular-weight components.

The standard test methods for oxidation stability of oil are the active oxygen method (AOCS Cd 1257 (89)), turbine oil oxidation stability test (ASTM D943), and rotary bomb oxidation test (ASTM D2722). These test methods are time-consuming, and comparison of the oxidative property with a greater number of oils is not so easy. Hence, it became a necessity to find an oxidation stability test that represents field performance within a short testing time. Thermogravimetric/differential thermal analysis (TGA/ DTA) is a fast method to find the oxidation stability of materials [18]. The weight loss and heat flow associated with the exothermic and endothermic reactions of a sample when heated at a constant rate or maintained at a constant temperature under different environments can be measured using TGA/DTA. The higher precision and sensitivity of TGA/DTA are the advantages compared to the conventional methods. Also, this test method requires a very small amount (milligrams) of the sample. Using TGA/ DTA, the oxidation stability of a material can be easily compared to any number of other available materials within a short time period.

Quantum chemical calculations are performed on constituent fatty acids of chaulmoogra oil to predict the tribological properties of the oil, and these values are then compared with experimental data. Oxidative stability of chaulmoogra oil is compared with other unsaturated oils and saturated coconut oil. Chaulmoogra oil exhibited the highest oxidation stability.

\section{Experiment Details}

2.1. Quantum Chemical Calculation. Quantum chemical calculations are based on quantum mechanics which consider property and behaviour of molecule as the interaction between the nuclei and electrons. Also, the molecular geometry is described as minimum energy arrangement of nuclei. All quantum chemical calculations are based on the time-independent Schrödinger wave equation. Original equation is applicable to single-electron single nuclei system, which can be generalized as a multielectron multinuclear system as follows [19]:

$$
\ddot{H} \psi=E \psi,
$$

where $E$ is the electronic energy in atomic units, $\psi$ is the many electrons wave function, and $\ddot{H}$ is the Hamiltonian operator corresponding to the multielectron, multinuclear system. 
An exact solution to the multielectron Schrödinger equation is too difficult. Born-Oppenheimer approximation, which assumes the nuclei do not move, deduce the electronic Schrödinger equation [19]:

$$
\ddot{H}^{e l} \psi^{e l}=E^{e l} \psi^{e l} .
$$

Hartree-Fock method [11], semiempirical methods such as Austin model 1 (AM1) or parameterization method 3 (PM3) [20, 21], and density functional method (DFT method) can be adopted to solve the electronic Schrödinger equation, but some recent studies proved that the DFT method gives a statistically more accurate QSAR (quantitative structure activity relationship) model [22-24]. Hence, DFT method and the molecular modelling package Spartan 18 are used in this study. It is difficult to model all the possible combinations of fatty acids for triglyceride. Hence, a typical triglyceride molecule of chaulmoogra oil is created by considering the major fatty acid constituents. Also, the quantum chemical calculations for the triglyceride molecule are time-consuming, and analysis of the fatty acid component is sufficient to assess the net electrostatic charge and orbital energies.

Initial energy minimization of the molecule is carried out with $\mathrm{MM}^{+}$force field [24]. Then, it is further optimized by Becker's three-parameter hybrid functional (B3LYP) and G6-31 basis vector [24].

Following quantum chemical descriptors are used in this study:

$Q_{r}$ : the net electrostatic charge, the atomic charge that matches with the electrostatic potential surrounding a molecule [25].

E_HOMO: energy of highest occupied molecular orbital which represents the least tightly held electrons.

E_LUMO: energy of lowest unoccupied molecular orbital which represents the easiest path for the addition of more electrons to the system.

$\Delta \mathrm{E}$ : orbital energy gap, i.e., the difference between E_HOMO and E_LUMO. Interaction between the two reacting species molecules will be stronger if the energy gap is small [25].

H_Form: energy required for a hypothetical reaction that creates molecules from the scattered electrons and nuclei.

Fatty acid composition of chaulmoogra oil, coconut oil, and sunflower oil is given in Table $1[26,27]$. Structure of significant fatty acids in coconut oil and chaulmoogra oil used for quantum chemical calculations is given in Figures 2 and 3 . The various fatty acids like myristic acid, palmitic acid, stearic acid, linoleic acid, ricinoleic acid, and eicosanoic acids that are commonly seen in vegetable oils are modelled and analyzed to find the influence of these acids on the net electrostatic potential and orbital energy gap. A detailed study is carried out for chaulmoogra oil and compared with coconut oil (a representative of saturated oil) and sunflower oil (a representative of unsaturated oil).
TABle 1: Fatty acid composition of chaulmoogra oil, coconut oil, and sunflower oil $[26,27]$.

\begin{tabular}{lccc}
\hline Fatty acid & Chaulmoogra (\%) & Coconut (\%) & $\begin{array}{c}\text { Sunflower } \\
(\%)\end{array}$ \\
\hline Hydnocarpic acid & 21 & - & - \\
Chaulmoogric & 15 & - & - \\
acid & 6 & - & - \\
Gorlic acid & - & 8 & - \\
Caprylic acid & - & 7 & - \\
Capric acid & - & 48 & - \\
Lauric acid & - & 16 & - \\
Myristic acid & 23 & 9 & 6 \\
Palmitic acid & 3 & 2 & 5 \\
Stearic acid & - & - & - \\
Palmitoleic acid & 26 & 7 & 20 \\
Oleic acid & 6 & 2 & 69 \\
Linoleic acid & &
\end{tabular}

2.2. Four Ball Test. Four ball test is the standard test method (ASTM D4172-94) to find the tribological characteristics of a lubricant base stock. The test is conducted using the four ball tester, Ducom Instruments, USA. The test conditions are as follows: three chromium alloy steel balls $(12.7 \mathrm{~mm}$ diameter $)$ are held together and immersed in the chaulmoogra oil. The load is applied on these steel balls for 60 minutes, through another rotating steel ball pressed on it. The standard test condition is $392 \mathrm{~N}, 1200 \mathrm{rpm}$, and $75^{\circ} \mathrm{C}$. Chromium alloy steel balls of $12.7 \mathrm{~mm}$ are used for the test. Specified duration for the test is 60 minutes. This test determines the coefficient of friction and the average wear scar diameter. The test is conducted on samples of chaulmoogra oil, coconut oil, and sunflower oil.

2.3. FTIR and NMR Spectroscopy. Thermo Nicolet Avatar 370 FTIR spectrometer is used for recording the infrared (IR) spectra. The scanning range of the instrument is 4000 to $400 \mathrm{~cm}^{-1}$, and the recorded data were averaged for thirtytwo scans. Solution-state NMR spectrometer $(400 \mathrm{MHz})$ is used for recording the proton spectra $\left({ }^{1} \mathrm{H}-\mathrm{NMR}\right)$ and carbon spectra $\left({ }^{13} \mathrm{C}-\mathrm{NMR}\right)$.

\subsection{Thermogravimetric/Differential Thermal Analysis (TGA/} $D T A$ ). Isothermal TGA/DTA is performed on chaulmoogra oil at $150^{\circ} \mathrm{C}$ under oxygen and nitrogen environment. The standard test methods for oxidation stability specify the test condition as $150^{\circ} \mathrm{C}$. So, the same temperature is specified for the isothermal TGA/DTA. At first, the sample is rapidly heated to $150^{\circ} \mathrm{C}$ under nitrogen and kept at that condition for 10 minutes. Then, it is switched over to oxygen at a flow rate of $100 \mathrm{ml} / \mathrm{min}$ and kept at the isothermal condition for $3 \mathrm{hrs}$ to find the oxidation stability. Diamond TG/DTA thermogravimetric analyzer, PerkinElmer, USA, is used for the analysis. Also, the test is conducted on nine other oils (coconut oil, sunflower oil, castor oil, sesame oil, groundnut oil, linseed oil, mustard oil, olive oil, and palm oil) for comparison. 


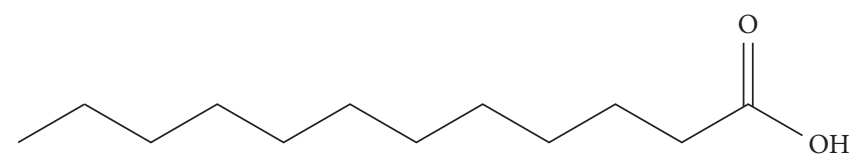

(a)

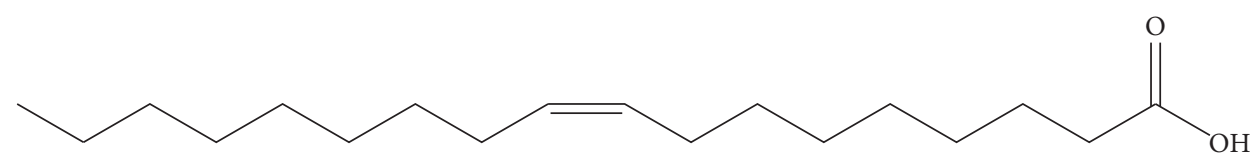

(b)

FIGURE 2: Structure of (a) lauric acid (C12:0) and (b) oleic acid (C18:1).

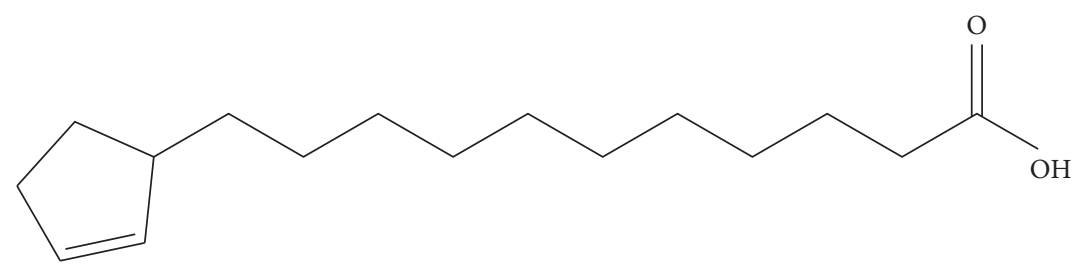

(a)

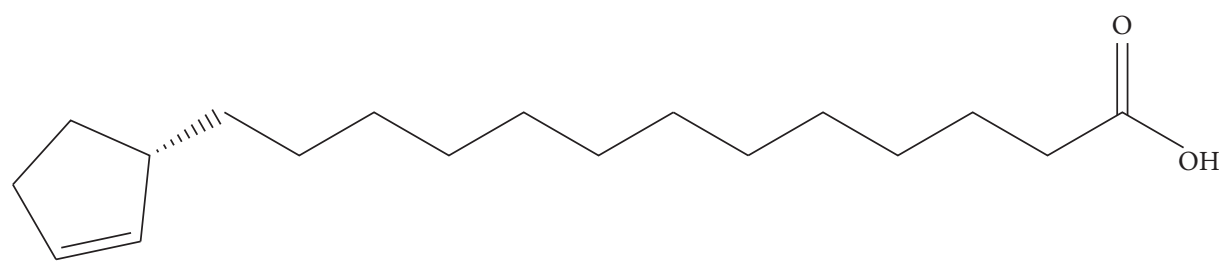

(b)

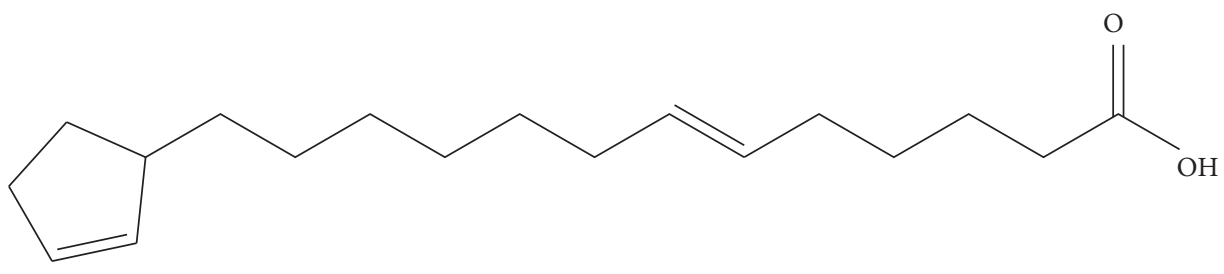

(c)

FIgURE 3: Structure of (a) hydnocarpic acid, (b) chaulmoogric acid, and (c) gorlic acid.

\section{Results and Discussion}

3.1. Quantum Chemical Analysis. A typical molecule of chaulmoogra oil is formed considering the relative abundance of fatty acids. As shown in Figure 4, the typical molecule is formed with hydnocarpic acid, chaulmoogric acid, and oleic acid. Quantum chemical calculations are performed on the constituent fatty acids of chaulmoogra oil and assessed the net electrostatic charge, orbital energies (HOMO and LUMO), and heat of formation. The net electrostatic charge predicts the physical adsorption, which is directly linked to the polarity. The electrostatic potential map of the significant fatty acids in chaulmoogra oil and coconut oil is shown in Figures 5-7. Also, the analysis is carried out on the typical molecule of chaulmoogra oil and the constituent fatty acids commonly found in vegetable oils (lauric acid, myristic acid, palmitic acid, stearic acid, oleic acid, and ricinoleic acid). The electrostatic potential map of the molecule of chaulmoogra oil is shown in Figure 8. It can be observed that the electrostatic potential obtained from the analysis of chaulmoogric acid and hydnocarpic acid is 0.57 , and the electrostatic potential of gorlic acid is 0.565 . The net electrostatic potential and the orbital energy gap of the fatty acids obtained from the analysis are plotted, as shown in Figure 9. As there is not much difference in electrostatic potential of different fatty acids, the physical adsorption and, hence, the value of the coefficient of friction are almost the same for all vegetable oils. This conclusion is in accordance with the experimental results given in Table 2 .

HOMO and HOMO $\{-1\}$ map and LUMO map of chaulmoogric acid and HOMO-LUMO map of the typical structure of chaulmoogra oil are given in Figures 10-12. It is observed that the HOMO map of chaulmoogric acid is centred around the pentene ring, and HOMO $\{-1\}$ and 


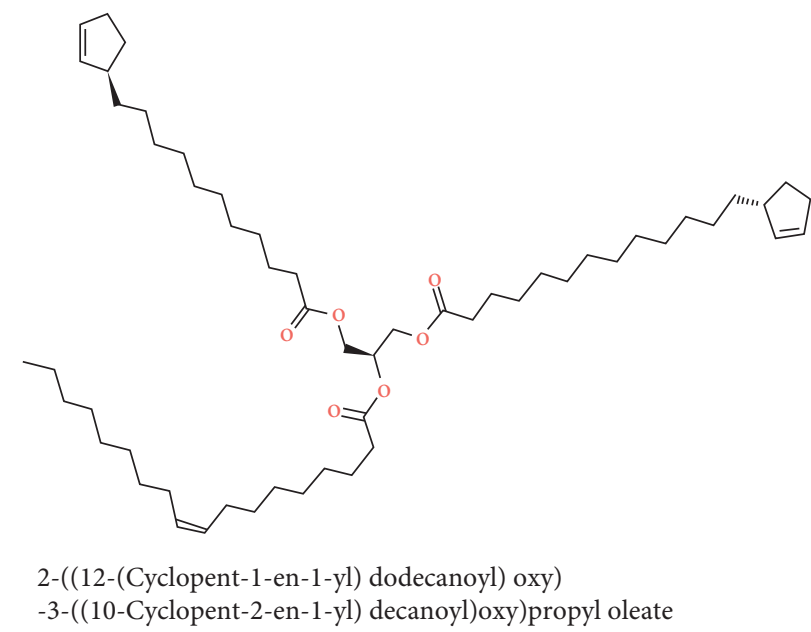

FigURE 4: Typical molecular structure of chaulmoogra oil with IUPAC name.

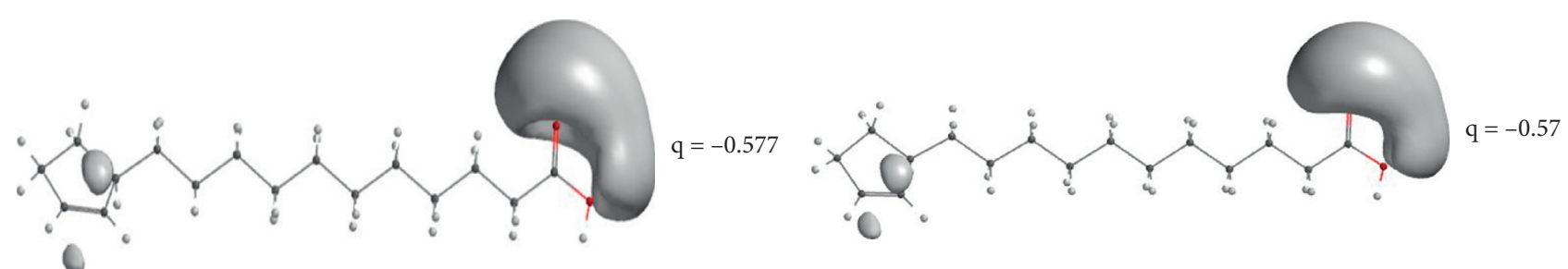

(a)

(b)

FIGURE 5: Electrostatic potential map of (a) chaulmoogric acid and (b) hydnocarpic acid.

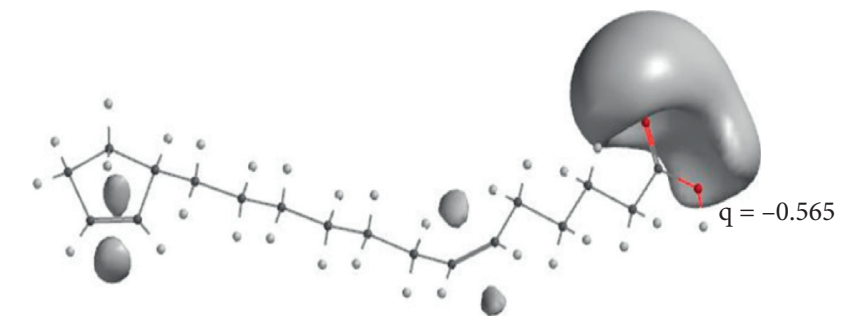

Figure 6: Electrostatic potential map of gorlic acid.

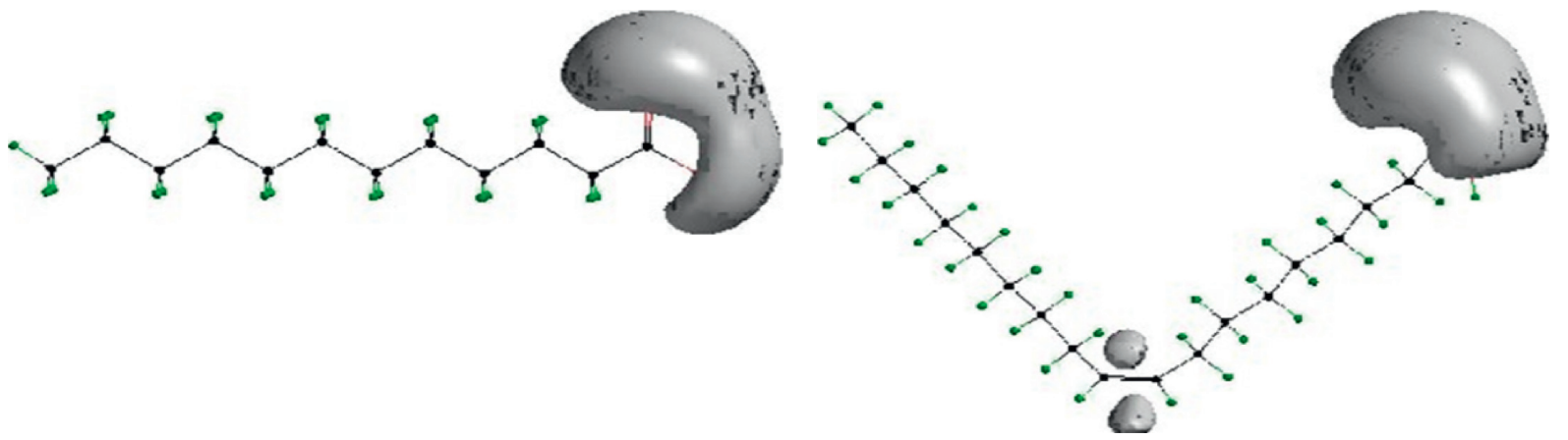

(a)

(b)

FIgURE 7: Electrostatic potential map of (a) lauric acid and (b) oleic acid. 


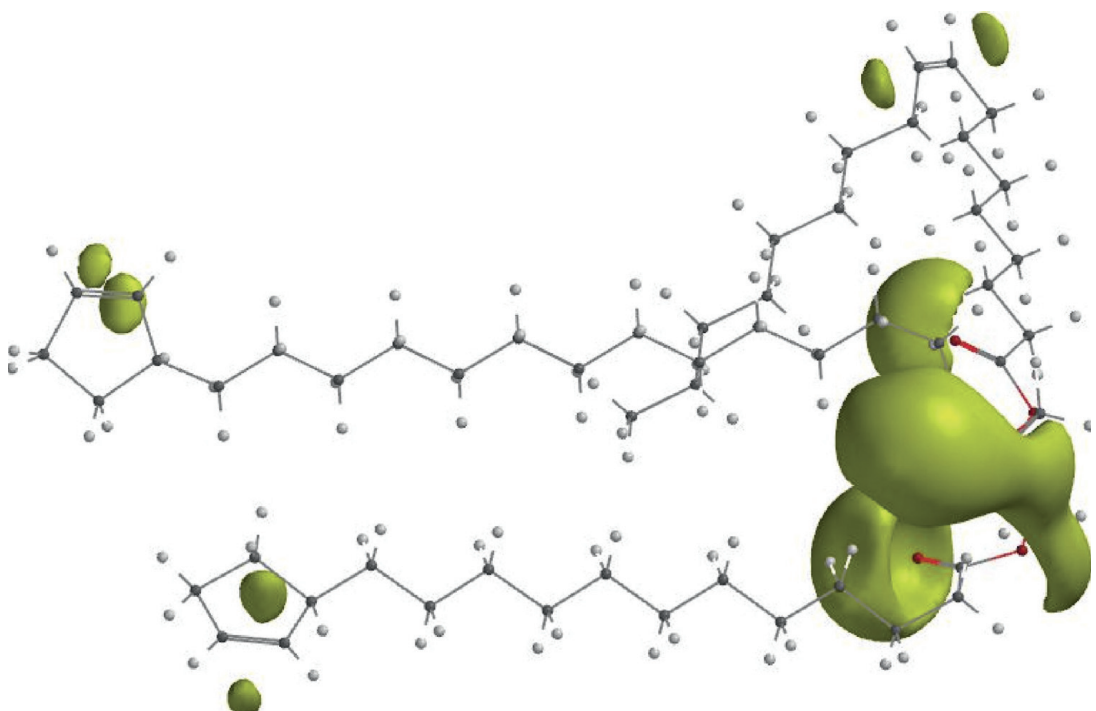

(a)

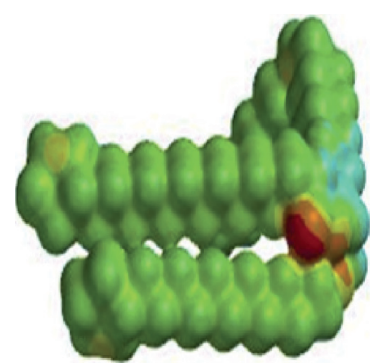

(b)

Figure 8: (a) Electrostatic potential map of a typical molecule of chaulmoogra oil; (b) potential mapping on density surface.

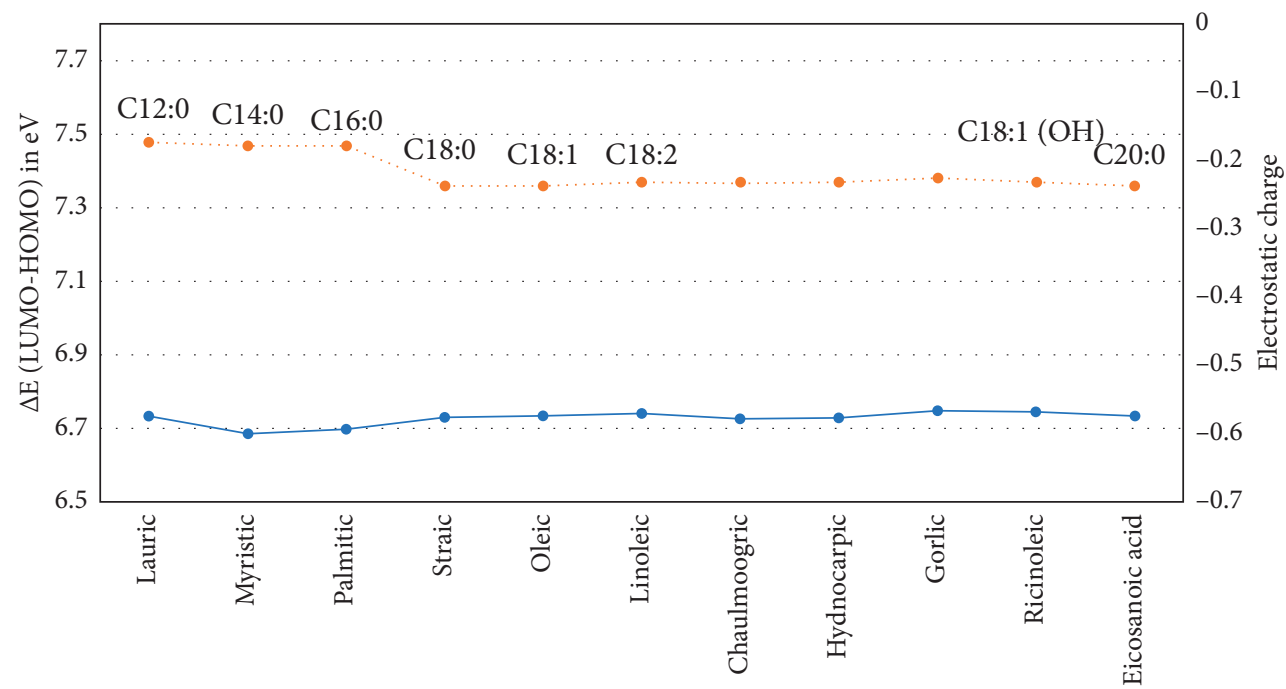

Fatty acids

$\begin{array}{ll}-\cdots \\ - & \text { E (LUMO-HOMO) }\end{array}$

FIGURE 9: Electrostatic charge and orbital energy gap plotted against fatty acids.

TABLE 2: Result of the tribological experiment.

\begin{tabular}{lcc}
\hline Vegetable oils & Coefficient of friction & Wear scar $(\mu \mathrm{m})$ \\
\hline Chaulmoogra oil & 0.059 & 611 \\
Coconut oil & 0.086 & 598 \\
Sunflower oil & 0.061 & 614 \\
\hline
\end{tabular}

LUMO maps are centred around the $\mathrm{COOH}$ group. The orbital energy gap can be taken as the difference between the LUMO and HOMO $\{-1\}$ energies. The orbital energy gap is an indication of chemical adsorption. The orbital energy gap of the chaulmoogra oil molecule is obtained as $6.8 \mathrm{eV}$ (energy difference between LUMO and HOMO $\{-3\}$ ). As indicated in Figure 9, the orbital energy gap of the main components of chaulmoogra oil is less than the orbital energy gap of lauric acid, which is the main constituent fatty acid of coconut oil. But it is comparable to oleic and linoleic acids, the major components of sunflower oil. Hence, it can be clinched that the orbital energy gap of chaulmoogra oil is less than that of the predominantly saturated coconut oil but comparable to the unsaturated sunflower oil. Also, the value of orbital energy gap of the polar head of the typical molecule of chaulmoogra oil is $6.8 \mathrm{eV}$, which is less than the orbital energy gap of the constituent fatty acids in chaulmoogra oil. 


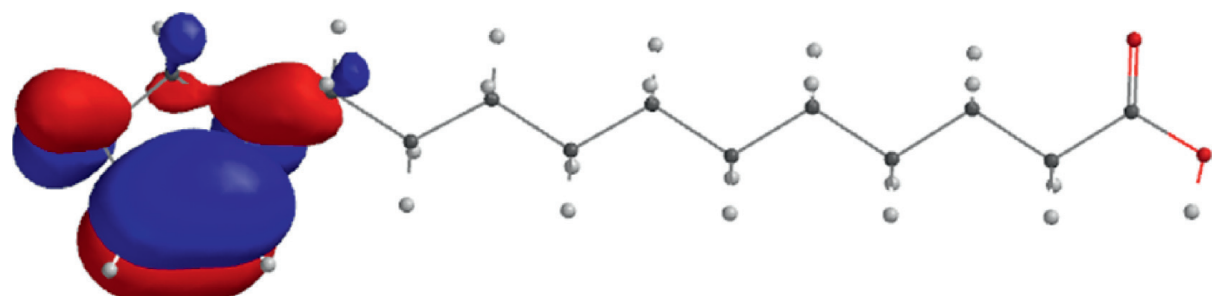

(a)

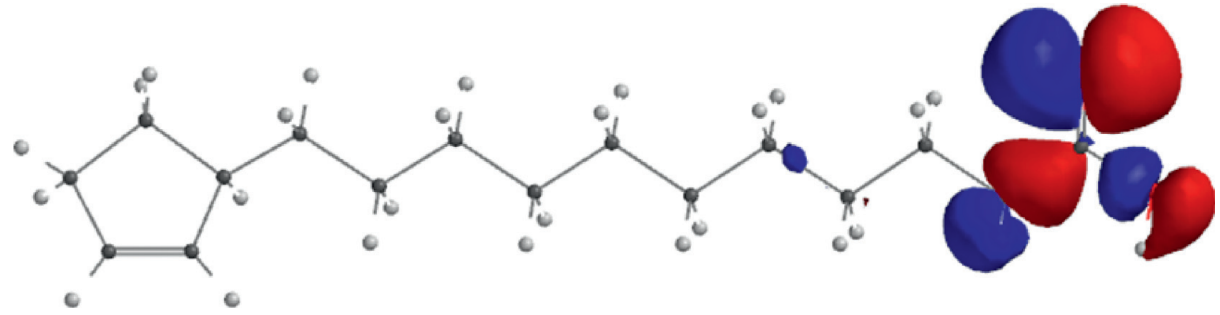

(b)

FIgURe 10: (a) HOMO and (b) HOMO $\{-1\}$ map of chaulmoogric acid.

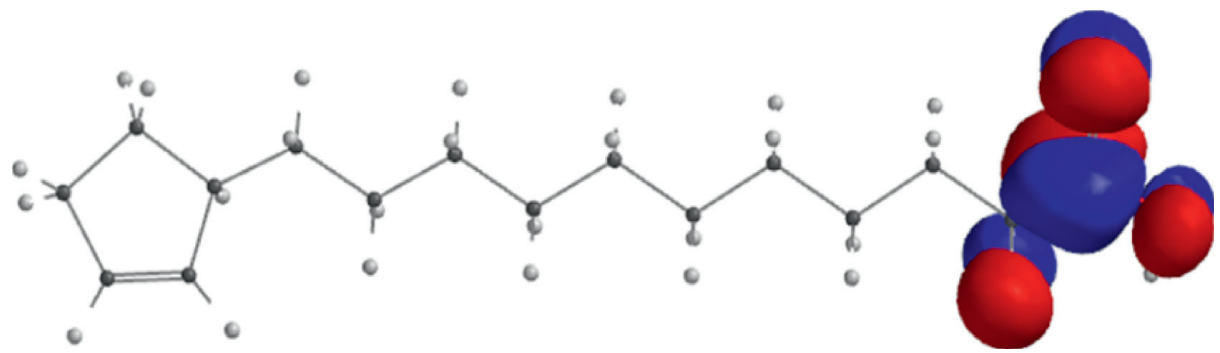

FigURE 11: LUMO map of chaulmoogric acid.

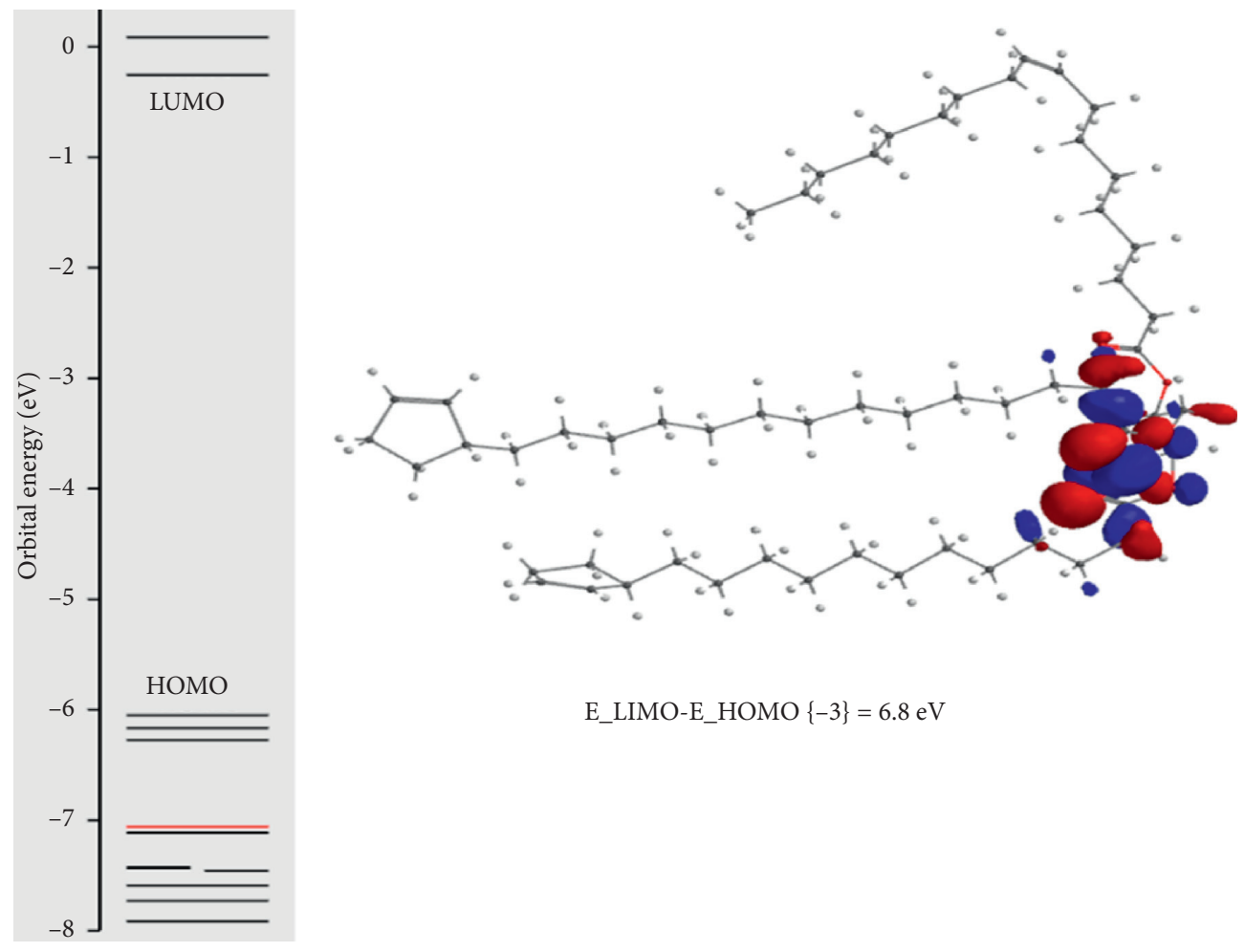

FIGURE 12: HOMO-LUMO map of the typical molecule of chaulmoogra oil. 


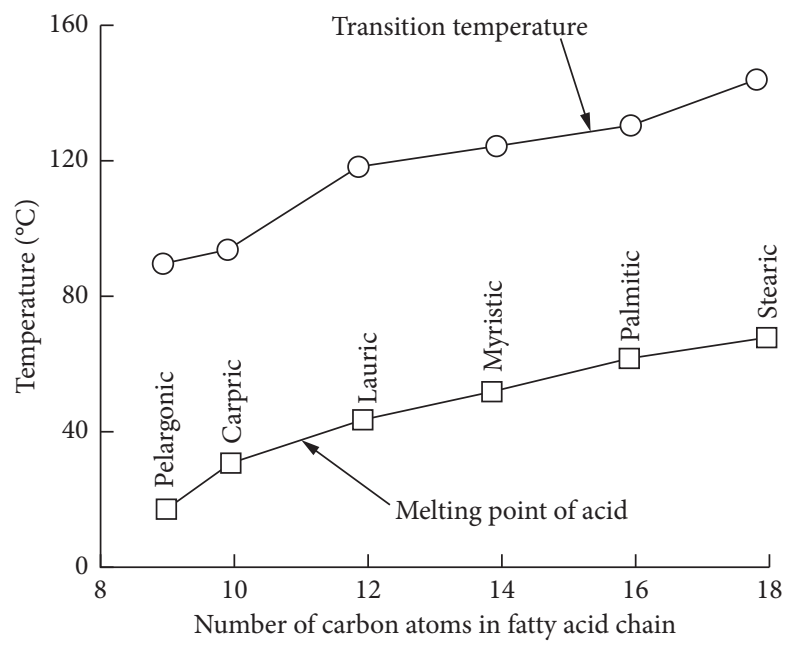

Figure 13: Transition temperature on the steel surface and melting of fatty acids as a function of chain length [14].

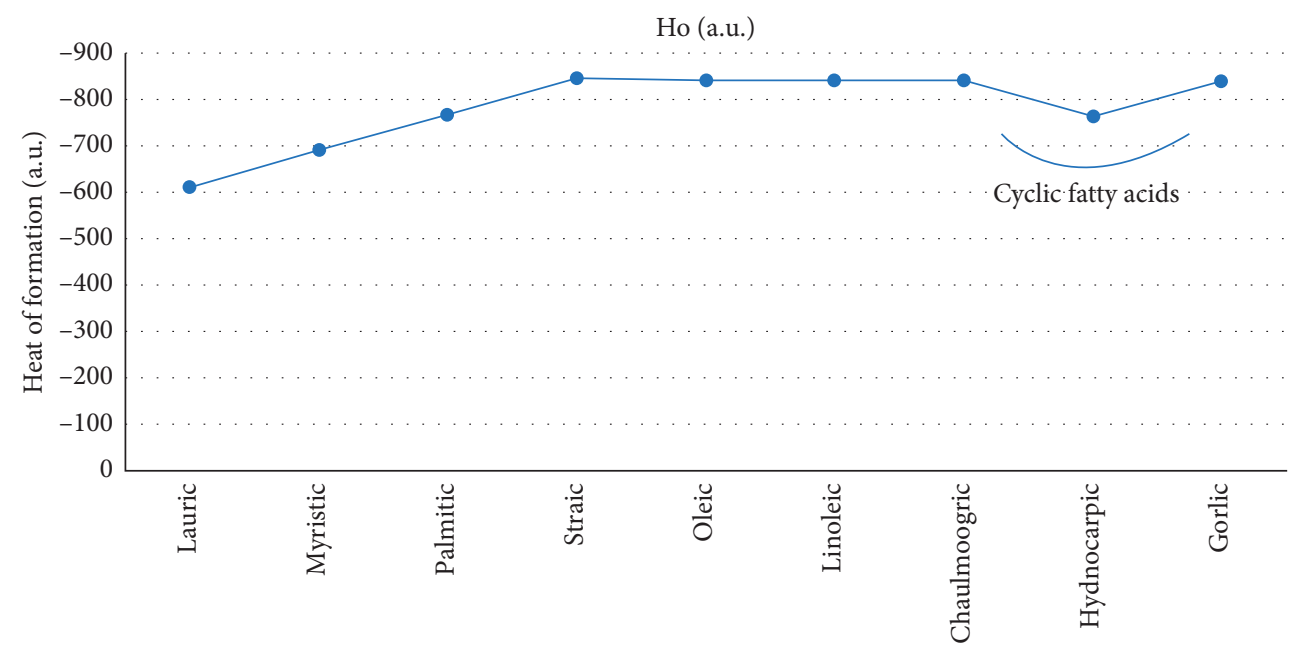

Fatty acids

FIGURE 14: The heat of formation of various fatty acids.

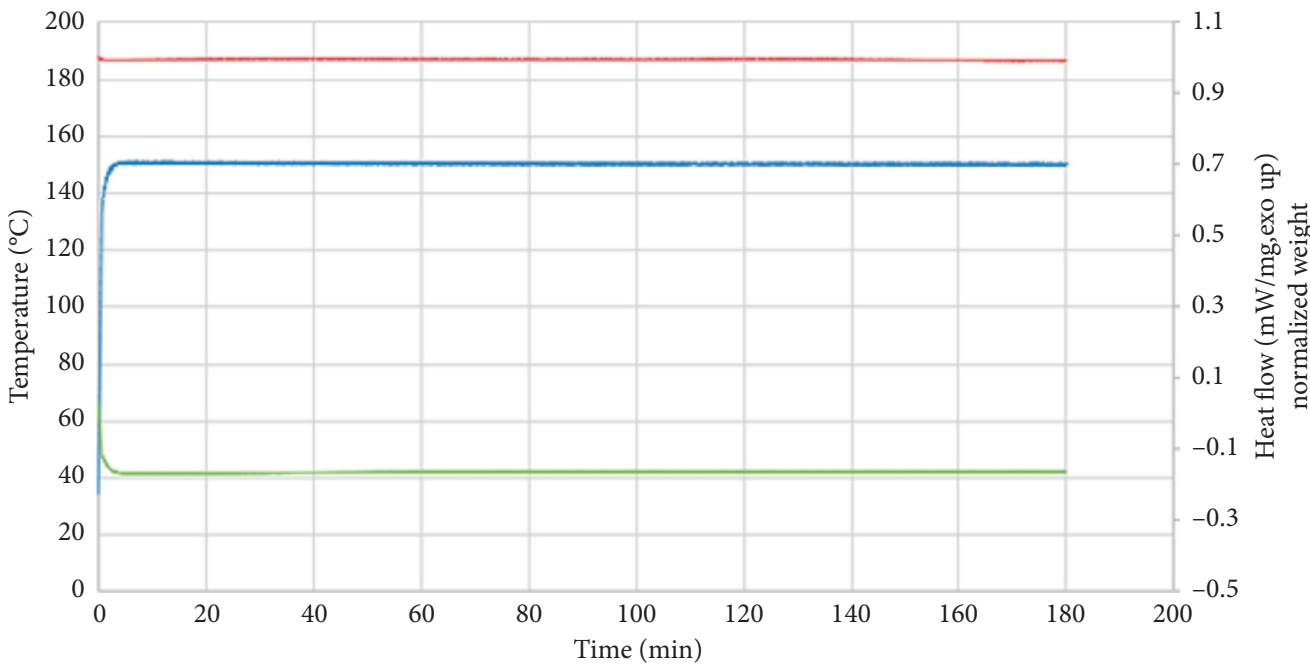

$$
\begin{array}{ll}
\text { Temp } \\
\text { N_Wt } \\
\text { HF }
\end{array}
$$

FIGURE 15: Heat flow, temperature, and normalized weight of chaulmoogra oil obtained from isothermal TGA in nitrogen. 


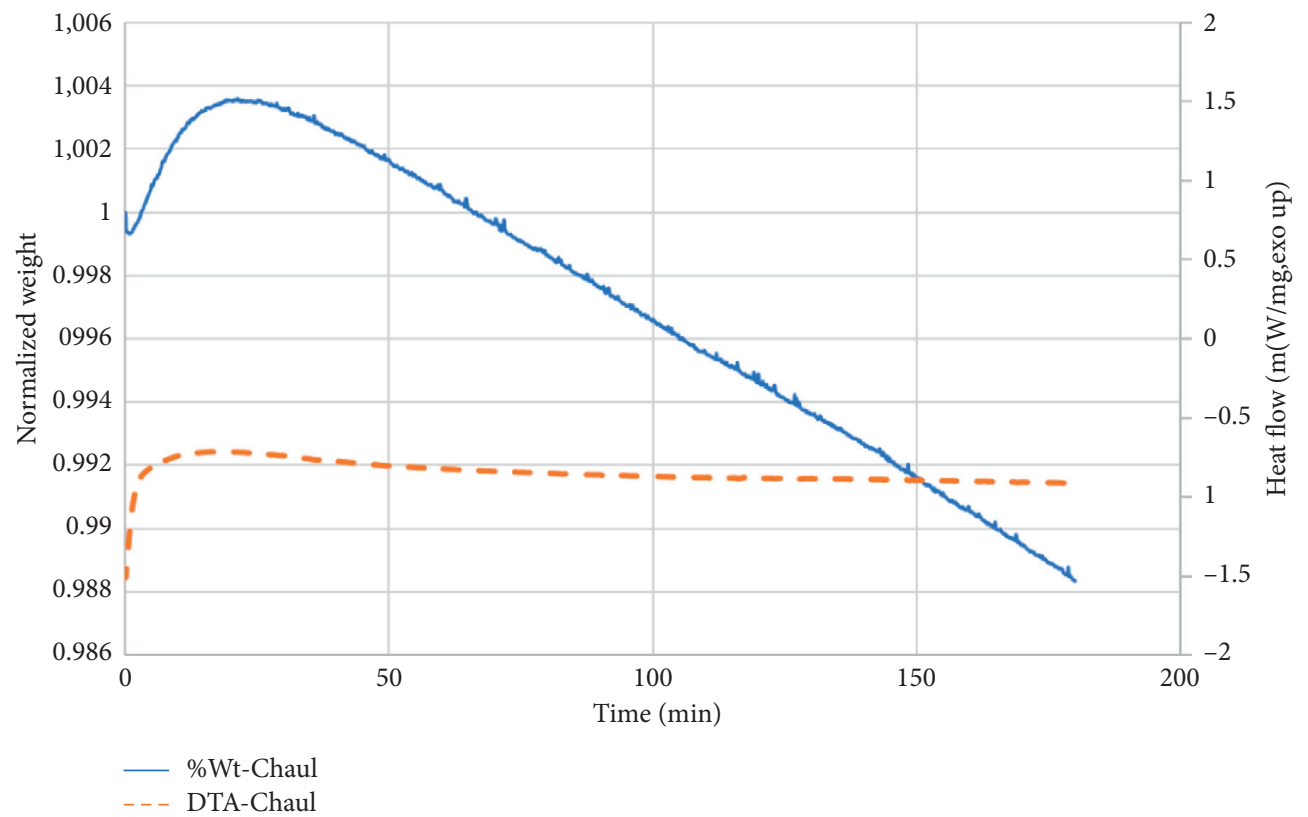

Figure 16: Heat flow, temperature, and normalized weight of chaulmoogra oil obtained from isothermal TGA in oxygen.

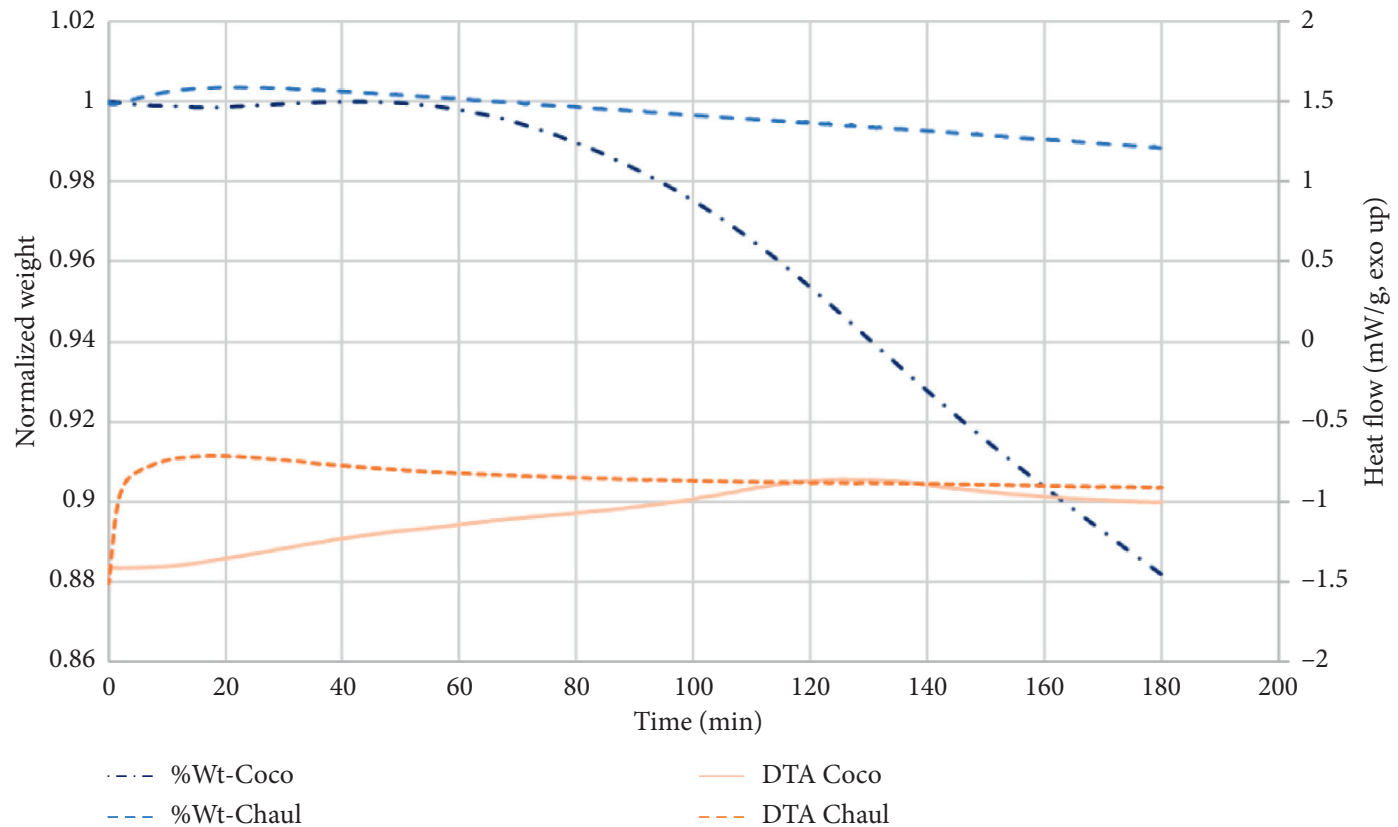

FIGURE 17: Isothermal TGA/DTA of chaulmoogra oil and coconut oil in oxygen.

If the orbital energy gap is less, the chemical adsorption is strong. Hence, we can predict a better tribological performance for chaulmoogra oil than the constituent fatty acids present in it.

The steric effect of the bent structure of unsaturated fatty acids is also a contributing factor to the friction and wear performance of vegetable oil molecules. Coconut oil is saturated vegetable oil with lauric acid (C12:0), myristic acid (C14:0), and palmitic acid (C16:0) as major saturated fatty acid constituents. Sunflower oil has oleic acid (C18:1), a monounsaturated oil fatty acid, as one of the major constituents. Since saturated fatty acids do not have any kinks in their structure due to double bonds with cis-configuration, they align normal to the metallic surface, providing better molecular packing. Monounsaturated fatty acids have only one double bond and hence have only one bend in their structure. High oleic vegetable oils were shown to have good tribological properties by many researchers compared to polyunsaturated oils [28]. Though 


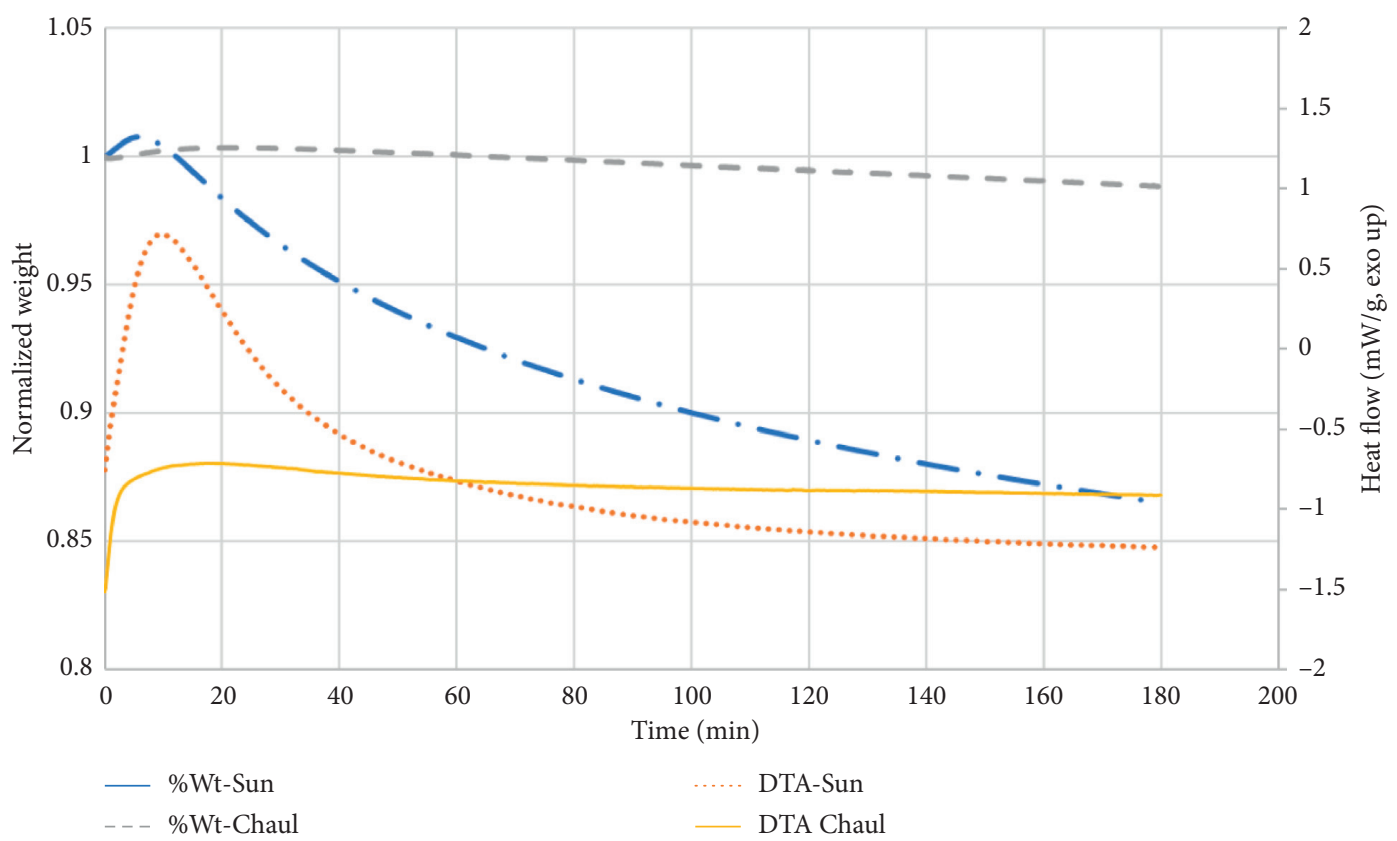

FIGURE 18: Isothermal TGA/DTA of chaulmoogra oil and sunflower oil in oxygen.

orbital energy gaps of chaulmoogric acid, hydnocarpic acid, gorlic acid, and oleic acids are lower than that of lauric acids, coconut oil has a favourable molecular structure (due to straight-chain fatty acids).

Quantum chemical analysis of chaulmoogra oil, as detailed above, predicts comparable friction and wear properties to that of coconut oil and sunflower oil (which are extensively studied and reported in [11]. The experimental result as given in Table 2 corroborates the conclusion drawn from quantum chemical calculations.

Bowden and Tabor plotted the transition temperature and melting point of various fatty acids as a function of carbon chain length and is given as Figure 13 [14]. The transition temperature into high wear regime increases with the increase in the number of carbon atoms in the fatty acid chain [14]. The heat of formation of various fatty acids is plotted and shown in Figure 14. The transition temperature into high wear regime for different fatty acids as depicted in Figure 13 shows good correspondence with the heat of formation of the fatty acids, as plotted in Figure 14. The heat of formation of constituent fatty acids of chaulmoogra oil is high compared to lauric acid, which is the major constituent of coconut oil. Coconut oil starts showing excessive wear above 120 [11], whereas for stearic acid, transition temperature into high wear regime is about 130 . Figure 14 shows that the major constituent fatty acids of chaulmoogra oil, namely, oleic, chaulmoogric, and gorlic acids (Table 1), have the heat of formation equal to that of stearic acid. Hence, we can predict a similar $(\sim 130)$ transition temperature for chaulmoogric acid.

3.2. Oxidative Property Using TGA/DTA. Heat flow, temperature, and normalized weight obtained from isothermal TGA of chaulmoogra oil in nitrogen and oxygen are shown in Figures 15 and 16. Heat flow and normalized weight are

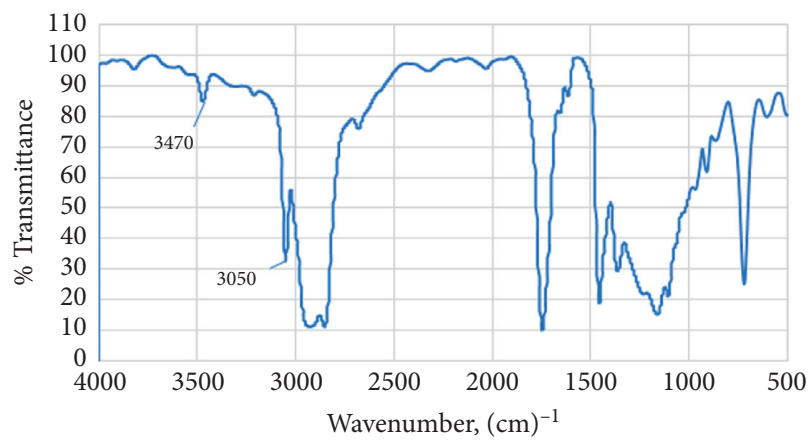

FIGURE 19: FTIR spectra of chaulmoogra oil.

constant in nitrogen. The oil shows thermal stability at $150^{\circ} \mathrm{C}$. But in oxygen, initially, it shows a weight gain due to peroxide formation, and then, weights decrease due to the volatile substances formed due to the decomposition of peroxide.

The comparison of the percentage weight and heat flow of chaulmoogra oil with the predominantly saturated coconut oil and unsaturated sunflower oil is shown in Figures 17 and 18. Coconut oil shows degradation after 60 minutes, but sunflower oil is polyunsaturated oil and shows an initial weight gain before degradation. Chaulmoogra oil is also unsaturated oil. However, it shows better oxidative stability compared to coconut oil and sunflower oil, which is attributed to the presence of the cyclic fatty acids which is more resistant to oxidative degradation compared to oleic acid or linoleic acid [29]. FTIR and NMR spectra given in Figures 19-21 can confirm the presence of unsaturation and cyclic components in chaulmoogra oil. IR peak at wave number $3050 \mathrm{~cm}^{-1}$ indicates the unsaturated system. Also, the chemical shift between 5 and $6 \mathrm{ppm}$ in ${ }^{\mathrm{I}} \mathrm{H}$ NMR 


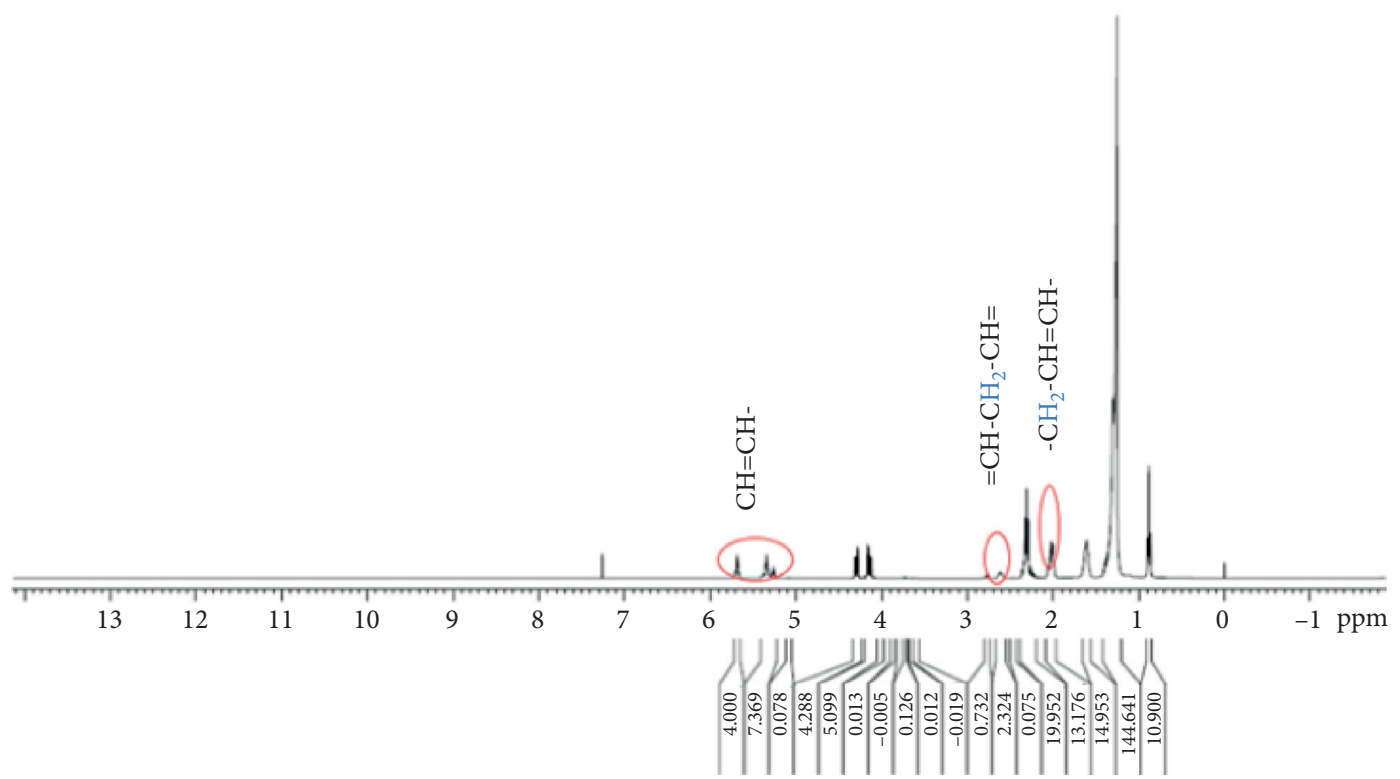

FIGURE 20: ${ }^{1} \mathrm{H}$ NMR spectra of chaulmoogra oil showing chemical shift corresponding to olefinic, bis-allylic, and allylic protons.
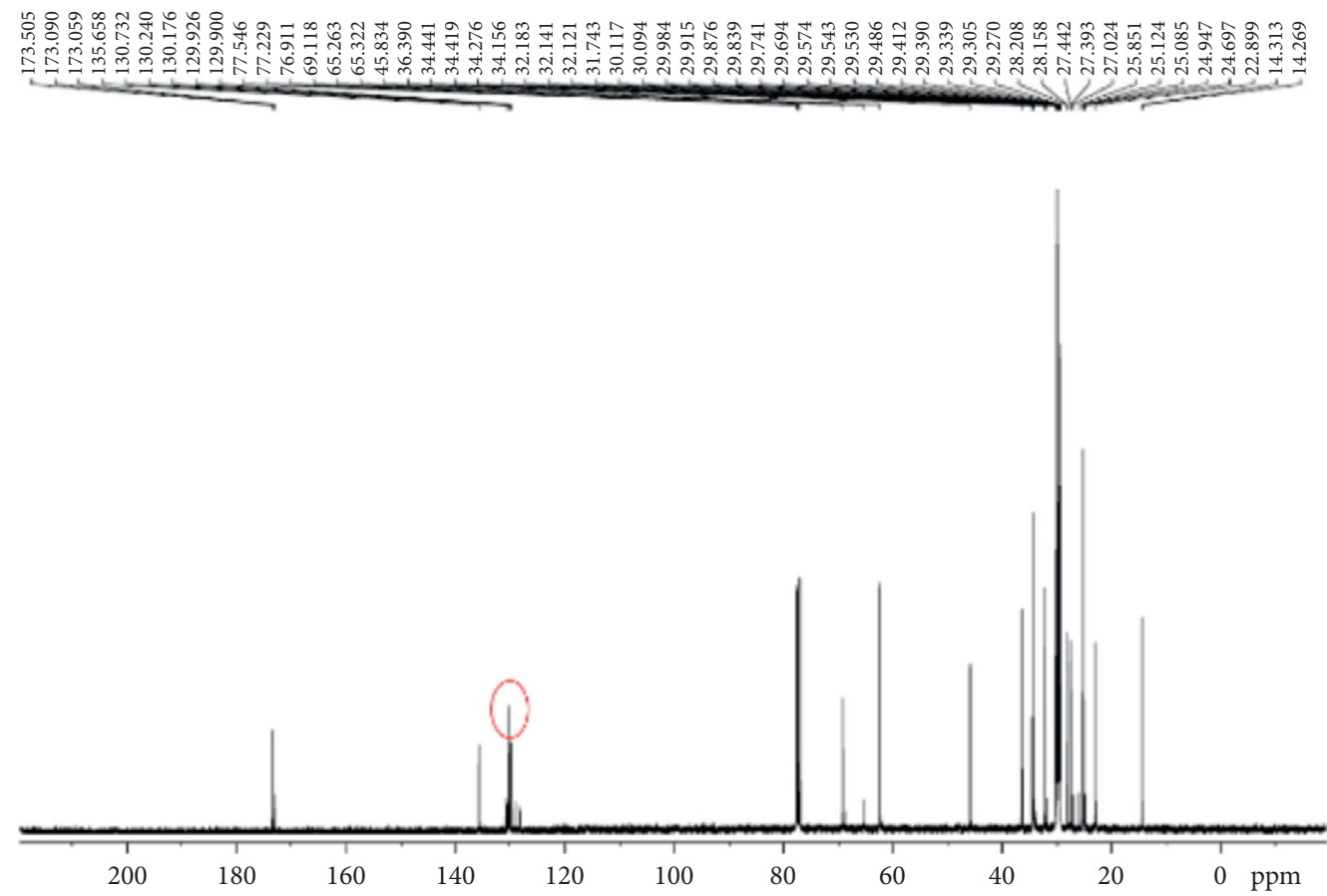

FIGURE 21: ${ }^{13} \mathrm{C}$ NMR spectra of chaulmoogra oil showing chemical shift corresponding to carbon connected to the vinylic proton in cyclopentene.

corresponds to the olefinic proton. The chemical shift at $\sim 2 \mathrm{ppm}$ and $\sim 2.6 \mathrm{ppm}$ corresponds to the allylic and bisallylic protons. The chemical shift in ${ }^{13} \mathrm{C}$ NMR and ${ }^{1} \mathrm{H}$ NMR at $\sim 130 \mathrm{ppm}$ and $\sim 5.56 \mathrm{ppm}$, respectively, confirms the olefinic carbon and proton in cyclopentene.
The isothermal TGA/DTA comparison of chaulmoogra oil with mustard oil, linseed oil, castor oil, sesame oil, coconut oil, groundnut oil, sunflower oil, olive oil, and palm oil in oxygen is shown in Figures 22 and 23. In the presence of oxygen, the oils start to decompose. The unsaturated oils 


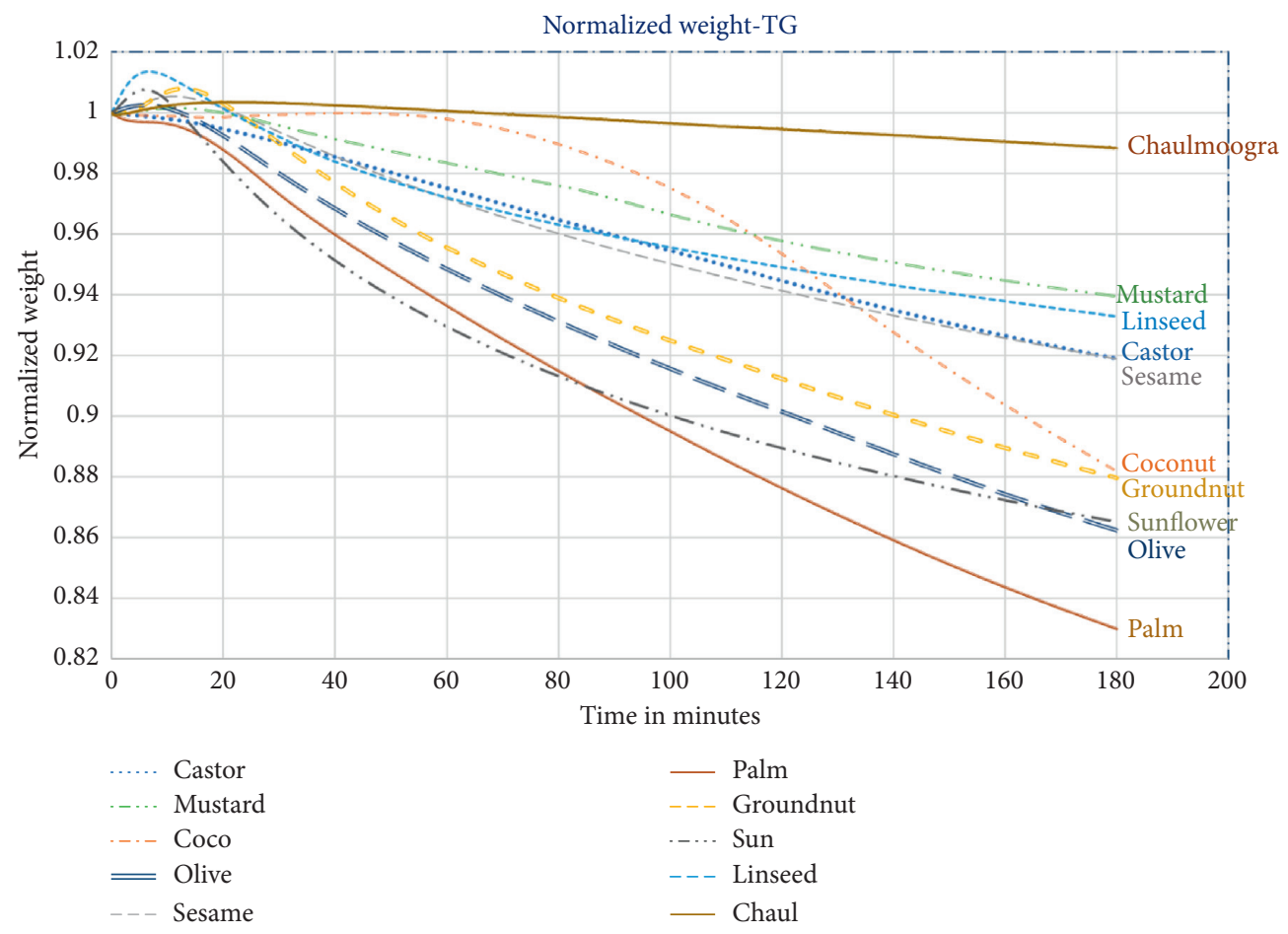

Figure 22: Isothermal TGA of different oils in oxygen.

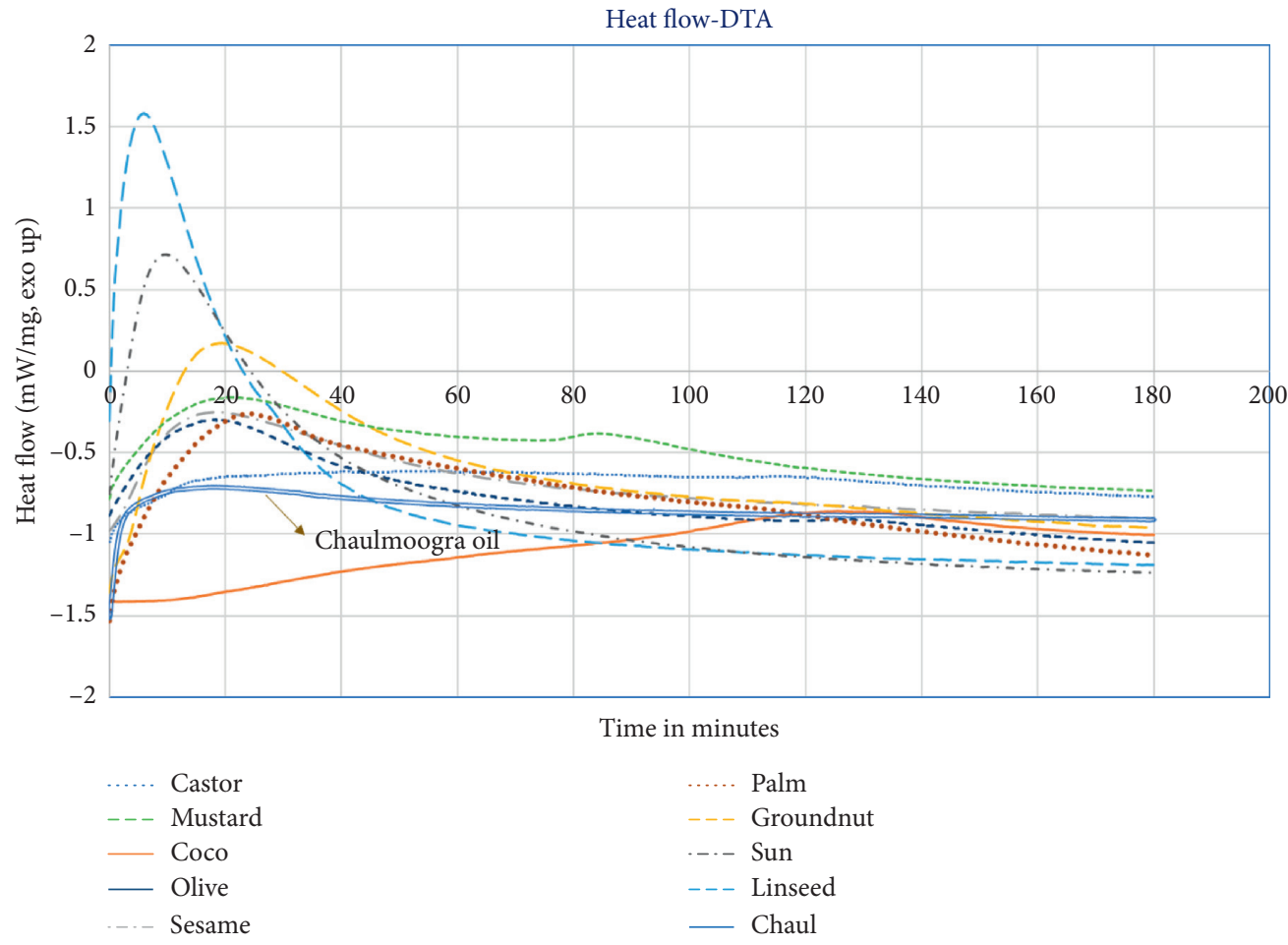

Figure 23: Isothermal DTA of different oils in oxygen.

gain weight due to oxygen uptake and peroxidation. The peroxide so formed then decomposes to form low-molecular-weight compounds. The change in weight is recorded for $3 \mathrm{hrs}$ keeping the oil sample in an isothermal condition.
The oxidative reactions are exothermic, and the vaporization of low volatile compounds is endothermic. The highest weight gain is for linseed oil. This is because the linseed oil possesses maximum unsaturation. The next highest weight 
gain is for sunflower oil. Oxidation stability of chaulmoogra oil is good compared to all other tested oils.

\section{Conclusions}

The following conclusions are made from the study:

(i) The quantum chemical parameters (HOMOLUMO energy gap, electrostatic charge, and the heat of formation) can be used to assess the friction and wear performance of vegetable oils.

(ii) The quantum chemical analysis of chaulmoogra oil predicts good friction and wear performance, which is in agreement with the experimental result.

(iii) Saturated and mono-unsaturated vegetable oils show comparatively better oxidation stability.

(iv) Chaulmoogra oil shows good oxidation stability (at $150^{\circ} \mathrm{C}$ ) among all other oils tested.

\section{Data Availability}

The data used to support the findings of this study are available from the corresponding author upon request.

\section{Disclosure}

This research received no specific grant from any funding agency.

\section{Conflicts of Interest}

The authors declare that there are no conflicts of interest regarding the publication of this paper.

\section{Acknowledgments}

The authors acknowledge the support provided by SAIF, CUSAT, Kochi, and NMR Centre, Bangalore. The authors would like to thank Dr. Prathapan S, Department of Applied Chemistry, CUSAT, Kochi, Kerala 682022, for his valuable suggestions.

\section{References}

[1] A. Adhvaryu and S. Z. Erhan, "Epoxidised soybean oil as a potential source of high-temperature lubricants," Industrial Crops and Products, vol. 15, no. 3, pp. 247-254, 2002.

[2] S. Z. Erhan and S. Asadauskas, "Lubricant base stocks from vegetable oils," Industrial Crops and Products, vol. 11, no. 2-3, pp. 277-282, 2000.

[3] P. Mercurio, K. A. Burns, and A. Negri, "Testing the ecotoxicology of vegetable versus mineral based lubricating oils: 1. Degradation rates using tropical marine microbes," Environmental Pollution, vol. 129, no. 2, pp. 165-173, 2004.

[4] H. M. Mobarak, N. M. Edzrol, H. H. Masjuki et al., "The prospects of biolubricants as alternatives in automotive applications," Renewable and Sustainable Energy Reviews, vol. 33, pp. 34-43, 2014.

[5] A. Adhvaryu, S. Z. Erhan, and J. M. Perez, "Tribological studies of thermally and chemically modified vegetable oils for use as environmentally friendly lubricants," Wear, vol. 257, no. 3-4, pp. 359-367, 2004.

[6] A. Zeman, A. Sprengel, D. Niedermeier, and M. Späth, "Biodegradable lubricant studies on thermo- oxidation of metalworking and hydraulic fluids by differential scanning calorimetry (DSC)," Thermochimica Acta, vol. 268, pp. 9-15, 1995.

[7] M. M. Gui, K. T. Lee, and S. Bhatia, "Feasibility of edible oil vs. non-edible oil vs. waste edible oil as biodiesel feedstock," Energy, vol. 33, no. 11, pp. 1646-1653, 2008.

[8] A. Adhvaryu, S. Z. Erhan, and J. M. Perez, "Wax appearance temperature of vegetable oils determined by differential scanning calorimetry: effect of triacylglycerol structure and its modifications," Thermochimica Acta, vol. 395, no. 1-2, pp. 191-200, 2003.

[9] R. E. Harry-O’kuru, G. Biresaw, and S. Gordon, J. Xu, Physical characteristics of tetrahydroxy and acylated derivatives of jojoba liquid wax in lubricant application," Journal of Analytical Methods in Chemistry, vol. 2018, Article ID 7548327, 12 pages, 2018

[10] J. W. Goodrum and D. P. Geller, "Influence of fatty acid methyl esters from hydroxylated vegetable oils on diesel fuel lubricity," Bioresource Technology, vol. 96, no. 7, pp. 851-855, 2005.

[11] N. H. Jayadas and K. P. Nair, "Study of the anti-wear properties of coconut oil using quantum chemical calculations and Tribological tests," Journal of Tribology, vol. 128, no. 3, pp. 654-659, 2006.

[12] N. H. Jayadas and K. P. Nair, "Elucidation of corrosion mechanism of vegetable oilbased lubricants," Journal of Tribology, vol. 129, no. 2, pp. 419-423, 2007.

[13] W. Huang, Y. Tan, B. Chen, J. Dong, and X. Wang, "The binding of anti-wear additives to iron surfaces: quantum chemical calculations and tribological tests," Tribology International, vol. 36, no. 3, pp. 163-168, 2003.

[14] F. P. Bowden and D. Tabor, "The nature of metallic wear," Friction and Lubrication of Solids (Oxford Classic Texts), pp. 285-298, Oxford University Press, New York, NY, USA, 2001.

[15] S. Ghnimi, E. Budilarto, and A. K. Eldin, "The new paradigm for lipid oxidation and insights to microencapsulation of omega-3 fatty acids," Comprehensive Reviews in Food Science and Food Safety, vol. 16, no. 6, pp. 1206-1218, 2017.

[16] M. A. Nicholls, T. Do, P. R. Norton, M. Kasrai, and G. M. Bancroft, "Review of lubrication of metallic surfaces by Zinc dialkyl dithiophosphates," Tribology International, vol. 38, no. 1, pp. 15-39, 2005.

[17] J. E. Field and D. R. Henderson, "Corrosion of metals in contact with new refrigerants/lubricants at various moisture and organic levels," ASHRAE Transactions, vol. 104, pp. 210-220, 1998.

[18] J. Dweck and C. M. S. Sampaio, "Analysis of the thermal decomposition of commercial vegetable oils in air by simultaneous TG/DTA," Journal of Thermal Analysis and Calorimetry, vol. 75, pp. 385-391, 2004.

[19] W. J. Hehre, A Guide to Molecular Mechanics and Quantum Chemical Calculations, pp. 21-88, Wave Function, Irvine, CA, USA, 2003.

[20] M. Dewar and E. G. Zoebisch, "Development and use of quantum mechanical molecular models. 76. AM1: a new general-purpose quantum mechanical molecular model," Journal of the American Chemical Society, vol. 115, 1993. 
[21] J. J. B. Stewart, "Optimization of parameters for semiempirical methods II. Applications," Journal of Computational Chemistrty, vol. 10, 1989.

[22] S. Trohalaki, E. Giffort, and R. Pachter, "Improved QSARs for predictive toxicology of halogenated hydrocarbons," Computers and Chemistry, vol. 24, no. 3-4, pp. 421-427, 2000.

[23] L. Zhang, J. Wan, and G. A. Yang, "DFT-based QSARs study of protoporphyrinogen oxidase inhibitors: phenyl triazolinones," Bioorganic and Medicinal Chemistry, vol. 12, no. 23, pp. 6183-6191, 2004.

[24] E. Eroglu, H. Turkmen, S. Guler, S. Palaz, and O. Oltulu, "A DFT based QSARs study of Acetazolamide/Sulfamide derivatives with carbonic anhydrase (CA-II) isozyme," International Journal of Molecular Sciences, vol. 8, no. 2, pp. 145-155, 2007.

[25] W. J. Hehre, A. J. Shusterman, and J. E. Nelson, The Molecular Modeling Work Book for Organic Chemistry, pp. 13-29, Wave Function, Irvin CA, USA, 1998.

[26] S. Salaji and N. H. Jayadas, "Evaluation of physicochemical and tribological properties of chaulmoogra (Hydnocarpus wightianus) oil as green lubricant base stock," Journal of Engineering Tribology, pp. 1-10, 2020.

[27] N. H. Jayadas and K. P. Nair, "Coconut oil as base oil for industrial lubricants-evaluation and modification of thermal, oxidative and low temperature properties," Tribology International, vol. 39, no. 9, pp. 873-878, 2006.

[28] S. Asadauskas, J. M. Perez, and J. L. Duda, "Lubrication properties of Castor oil- potential base stock for biodegradable lubricants," Chemical Engineering, vol. 53, no. 12, pp. 35-40, 1997.

[29] L. Bruhl, "Fatty acid alteration in oils and fats during heating and frying," European Journal of Lipid Science and Technology, vol. 116, no. 6, pp. 707-715, 2014. 